\title{
Association of Fenofibrate Therapy With Long-term Cardiovascular Risk in Statin-Treated Patients With Type 2 Diabetes
}

Marshall B. Elam, PhD, MD; Henry N. Ginsberg, MD; Laura C. Lovato, MS; Marshall Corson, MD; Joseph Largay, PA-C; Lawrence A. Leiter, MD; Carlos Lopez, MD, MS; Patrick J. O'Connor, MD, MPH; Mary Ellen Sweeney, MD; Daniel Weiss, MD; William T. Friedewald, MD; John B. Buse, MD, PhD; Hertzel C. Gerstein, MD; Jeffrey Probstfield, MD; Richard Grimm, MD, PhD; Faramarz Ismail-Beigi, MD, PhD; David C. Goff Jr, MD, PhD;

Jerome L. Fleg, MD; Yves Rosenberg, MD; Robert P. Byington, PhD; for the ACCORDION Study Investigators

IMPORTANCE Patients with type 2 diabetes are at high risk of cardiovascular disease (CVD) in part owing to hypertriglyceridemia and low high-density lipoprotein cholesterol. It is unknown whether adding triglyceride-lowering treatment to statin reduces this risk.

OBJECTIVE To determine whether fenofibrate reduces CVD risk in statin-treated patients with type 2 diabetes.

DESIGN, SETTING, AND PARTICIPANTS Posttrial follow-up of the Action to Control Cardiovascular Risk in Diabetes (ACCORD) Lipid Study between July 2009 and October 2014; 5 years of follow-up were completed for a total of 9.7 years at general community and academic outpatient research clinics in the United States and Canada. Of the original 5518 ACCORD Lipid Trial participants, 4644 surviving participants were selected based on the presence of type 2 diabetes and either prevalent CVD or CVD risk factors and high-density lipoprotein levels less than $50 \mathrm{mg} / \mathrm{dL}$ ( $<55 \mathrm{mg} / \mathrm{dL}$ for women and African American individuals).

INTERVENTIONS Passive follow-up of study participants previously treated with fenofibrate or masked placebo.

MAIN OUTCOMES AND MEASURES Occurrence of cardiovascular outcomes including primary composite outcome of fatal and nonfatal myocardial infarction and stroke in all participants and in prespecified subgroups.

RESULTS The 4644 follow-on study participants were broadly representative of the original ACCORD study population and included significant numbers of women $(n=1445 ; 31 \%)$, nonwhite individuals ( $n=1094 ; 21 \%$ ), and those with preexisting cardiovascular events ( $n=1620 ; 35 \%$ ). Only $4.3 \%$ of study participants continued treatment with fenofibrate following completion of ACCORD. High-density lipoprotein and triglyceride values rapidly equalized among participants originally randomized to fenofibrate or placebo. Over a median total postrandomization follow-up of 9.7 years, the hazard ratio (HR) for the primary study outcome among participants originally randomized to fenofibrate vs placebo (HR, 0.93; 95\% $\mathrm{Cl}, 0.83-1.05 ; P=.25$ ) was comparable with that originally observed in ACCORD (HR, 0.92; $95 \% \mathrm{Cl}, 0.79-1,08 ; P=.32$ ). Despite these overall neutral results, we continued to find evidence that fenofibrate therapy effectively reduced CVD in study participants with dyslipidemia, defined as triglyceride levels greater than $204 \mathrm{mg} / \mathrm{dL}$ and high-density lipoprotein cholesterol levels less than $34 \mathrm{mg} / \mathrm{dL}$ (HR, 0.73; 95\% Cl, 0.56-0.95).

CONCLUSIONS AND RELEVANCE Extended follow-up of ACCORD-lipid trial participants confirms the original neutral effect of fenofibrate in the overall study cohort. The continued observation of heterogeneity of treatment response by baseline lipids suggests that fenofibrate therapy may reduce CVD in patients with diabetes with hypertriglyceridemia and low high-density lipoprotein cholesterol. A definitive trial of fibrate therapy in this patient population is needed to confirm these findings.

TRIAL REGISTRATION clinicaltrials.gov Identifier: NCT00000620.

JAMA Cardiol. 2017;2(4):370-380. doi:10.1001/jamacardio.2016.4828 Published online December 28, 2016. Corrected on February 6, 2017.
Supplemental content
Author Affiliations: Author affiliations are listed at the end of this article.

Group Information: The ACCORDION Study Investigators are listed in Supplement 1.

Corresponding Author: Marshall B. Elam, PD, MD, Division of Cardiovascular Diseases, Departments of Pharmacology and Medicine, University of Tennessee Health Sciences Center Memphis, 215 TSRB, 71 S Manassas St, Memphis, TN 38103 (melam@uthsc.edu). 
C ardiovascular disease (CVD) risk is increased in patients with type 2 diabetes, particularly in older patients and those with other risk factors for CVD. Compared with their counterparts without diabetes, the relative risk of fatal and nonfatal CVD events can be 2- to 3-fold and 3- to 4-fold higher, respectively, in men and women with diabetes. ${ }^{1-4}$ Increased risk of CVD in type 2 diabetes is attributable in part to the high prevalence of associated risk factors including hypertension and diabetic dyslipidemia, the latter characterized by elevated plasma triglyceride levels and low plasma levels of high-density lipoprotein cholesterol (HDL-C). 5,6 The Action to Control Cardiovascular Risk in Diabetes (ACCORD) was a randomized, multicenter, partial double $2 \times 2$ factorial trial that enrolled 10251 individuals with type 2 diabetes mellitus who were at high risk of CVD events. The ACCORD study tested the effects of intensive control of blood glucose, blood pressure, and plasma lipids on CVD risk in patients with type 2 diabetes. ${ }^{7}$

The ACCORD-Lipid was conducted in a subset of 5518 ACCORD participants and tested the hypothesis that combination statin-fibrate therapy would more effectively reduce CVD risk compared with statin alone in patients with type 2 diabetes. Although triglycerides and HDL-C are widely recognized as biomarkers of CVD risk, ${ }^{8}$ it is uncertain whether pharmacologic therapy directed toward lowering triglyceride levels and raising HDL-C effectively reduces that risk, particularly when added to statin therapy. In ACCORDLipid, following a mean 4.7 years of treatment, the rate of occurrence of the composite primary outcome measure of myocardial infarction, stroke, and fatal CVD was not significantly lower in participants randomized to fenofibrate therapy compared with those randomized to placebo. ${ }^{9}$ There were also no significant differences between the 2 study groups for any of the prespecified secondary outcomes, including fatal cardiovascular events, nonfatal MI, or nonfatal stroke. ${ }^{9}$ In contrast to these findings, prespecified subgroup analyses in ACCORD-Lipid detected significant heterogeneity in treatment effect by baseline lipids suggesting benefit for those with dyslipidemia, predefined as having both high triglycerides and low HDL-C levels at baseline. Heterogeneity in fenofibrate response was also noted by sex, with evidence of benefit for men vs possible harm in women.

The neutral overall CVD outcomes of the glycemia, blood pressure, and lipid treatment arms of ACCORD, along with the findings of heterogeneity of the effect of fenofibrate on cardiovascular outcomes in ACCORD-Lipid, ${ }^{9-12}$ supported the need for additional follow-up of participants to detect emergence of long-term "legacy" effects of the interventions and to explore the findings of heterogeneity by baseline dyslipidemia and sex. The ACCORD Follow-On Study (ACCORDION) was designed and conducted for this purpose. In this study, we describe the outcome of extended observational follow-up of ACCORD-Lipid participants in ACCORDION. The extended follow-up findings of the ACCORD blood pressure and glycemia intervention groups have been or will be reported separately. ${ }^{13}$

\section{Key Points}

Question Does fenofibrate reduce cardiovascular disease risk in statin-treated patients with type 2 diabetes?

Findings In this posttrial follow-up of the Action to Control Cardiovascular Risk in Diabetes Lipid Study, fenofibrate therapy was associated with reduced cardiovascular disease in study participants with dyslipidemia, defined as triglyceride levels greater than $204 \mathrm{mg} / \mathrm{dL}$ and high-density lipoprotein cholesterol levels less than $34 \mathrm{mg} / \mathrm{dL}$.

Meaning Extended follow-up of ACCORD-lipid trial participants confirms the original neutral effect of fenofibrate in the overall study cohort; the continued observation of heterogeneity of treatment response by baseline lipids suggests that fenofibrate therapy may reduce CVD in patients with diabetes with hypertriglyceridemia and low high-density lipoprotein cholesterol.

\section{Methods}

ACCORD and ACCORDION Study Design, Eligibility, and Conduct

The rationale, design, and primary results of ACCORD were previously reported. ${ }^{9-12,14}$ Briefly, all participants underwent 2 sequential randomizations, the first to intensive vs standard glucose-lowering therapy in the overarching glycemia trial and the second to either intensive vs standard blood pressure or lipid therapy in the ACCORD-Blood Pressure or ACCORDLipid trials, respectively, in a partial double $2 \times 2$ design (Figure 1). The primary outcome for all 3 trials was the first occurrence of a nonfatal myocardial infarction (MI), nonfatal stroke, or death from a cardiovascular cause. Participants were recruited from 77 clinical sites across the United States and Canada between January 2001 and October 2005. Follow-up of ACCORD ended in June of 2009.

The ACCORD-Lipid trial, conducted in 5518 participants, was a randomized, placebo-controlled, double-blind treatment arm of ACCORD in which all participants received simvastatin to attain contemporary guideline-based low-density lipoprotein cholesterol (LDL-C) treatment goals ${ }^{7,15}$ and were randomly assigned to receive either fenofibrate or matched placebo. In addition to fulfilling the overall ACCORD eligibility criteria, participants were specifically eligible for ACCORDLipid if they also met the following: (1) LDL-C levels between $60 \mathrm{mg} / \mathrm{dL}$ and $180 \mathrm{mg} / \mathrm{dL}$ (to convert to millimoles per liter, multiply by 0.0259), inclusive; (2) HDL-C levels less than 55 $\mathrm{mg} / \mathrm{dL}$ for women and African American individuals less than $50 \mathrm{mg} / \mathrm{dL}$ for all other groups (to convert to millimoles per liter, multiply by 0.0259); and (3) triglyceride levels less than $750 \mathrm{mg} / \mathrm{dL}$ if not receiving a lipid medication or less than 400 $\mathrm{mg} / \mathrm{dL}$ if receiving a lipid medication (to convert to millimoles per liter, multiply by 0.0113). All participants provided written informed consent. Open-labeled simvastatin therapy began at the randomization visit, and the dose was modified over time in response to changing guidelines. ${ }^{15}$ The masked fenofibrate/placebo medication was fenofibrate was $160 \mathrm{mg} / \mathrm{d}$ in participants with normal renal function and $48 \mathrm{mg} / \mathrm{d}$ for 
Figure 1. Action to Control Cardiovascular Risk in Diabetes (ACCORD)/ ACCORD Follow-On Study (ACCORDION) CONSORT Diagram

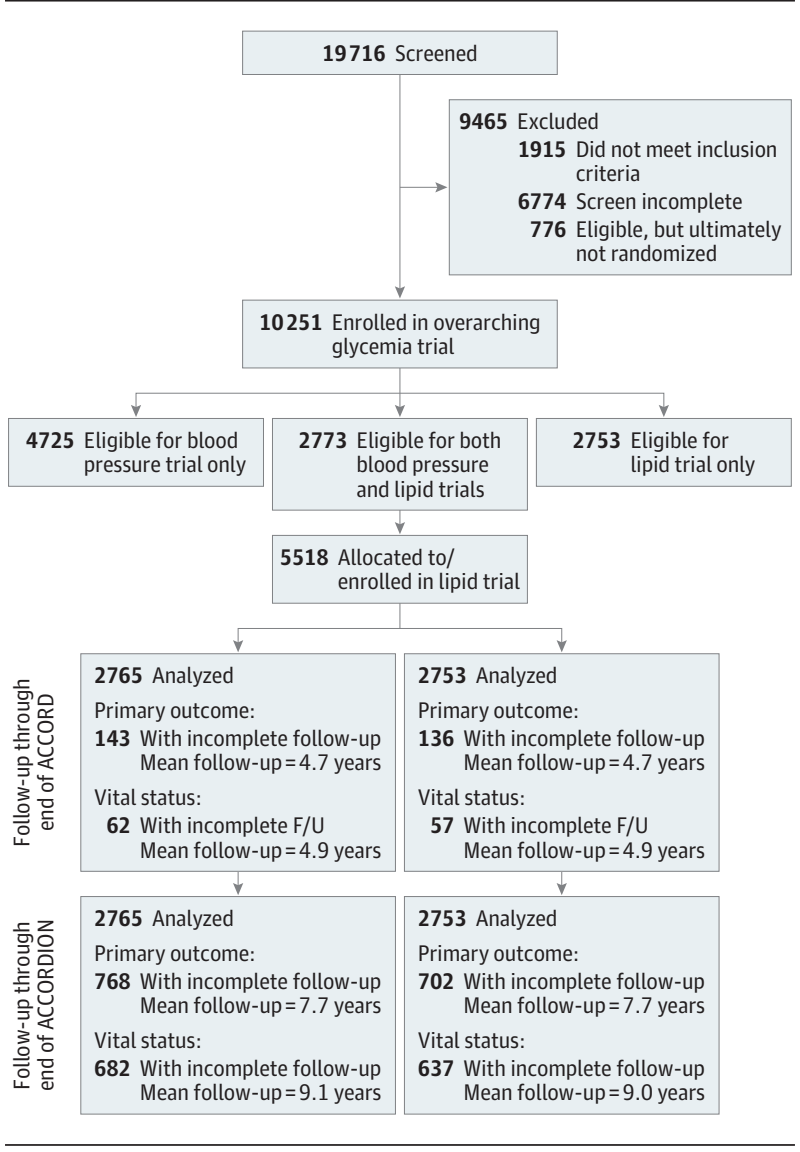

In the ACCORD study, eligible participants underwent 2 sequential randomizations, the first to intensive vs standard glycemia therapy followed by a second randomization to intensive vs standard blood pressure or lipid treatment in a double $2 \times 2$ factorial design. In the ACCORD lipid trial, participants were randomized to either fenofibrate or placebo on a background of statin therapy. Following completion of ACCORD, a total of 4644 surviving Lipid trial participants agreed to extended passive (nontreatment) follow-up in ACCORDION. Rates of occurrence of cardiovascular end points during the original study and during extended follow-up were assessed in all study participants with censoring for the last date of follow-up.

those with an estimated glomerular filtration rate less than $50 \mathrm{~mL} / \mathrm{min} / 1.73 \mathrm{M}^{215}$

The ACCORD closeout visits were completed by June 2009 . Following approval by the coordinating center (Wake Forest University) and participating clinical site institutional review board approvals, consenting participants were invited at these final trial visits to participate in the posttrial, nontreatment, observation-only ACCORDION study. Participant contacts were scheduled approximately every 6 months. These consisted of 2 in-clinic with 4 additional telephone visits annually. Information was collected regarding CVD events, hospitalizations, and medication usage. In-clinic visits also included a physical examination and, at the first and last visits, collection of urine and blood samples for analysis, a standardized electrocardiogram recording, and health-related quality of life data. Follow-up ended on October 31, 2014, or 60 months postACCORD, for a total of 5 years of posttrial observation. More detailed information can be found in the ACCORDION trial protocol (Supplement 2). A complete listing of the ACCORD/ ACCORDION study group is provided in Supplement 1.

\section{Prespecified Outcomes, Subgroups, Event Ascertainment}

The prespecified primary outcome for ACCORDION-Lipid was the same as for ACCORD: the first postrandomization occurrence of a major cardiovascular event, specifically nonfatal myocardial infarction, nonfatal stroke, or death from cardiovascular causes. ${ }^{7}$ Secondary outcomes included an expanded composite macrovascular outcome, a major coronary heart disease event, nonfatal myocardial infarction, nonfatal stroke, total fatal/nonfatal stroke, all-cause mortality, cardiovascular mortality, total fatal/nonfatal congestive heart failure, and CVD-free survival. The consistency of intervention effects was also examined across the same prespecified baseline subgroups examined in ACCORD including sex, age, race/ethnicity, baseline CVD history, hemoglobin $\mathrm{Al}_{\mathrm{c}}$, glycemia treatment assignment, tertiles of LDL-C, HDL-C , and triglyceride, as well as in those with and without dyslipidemia at baseline (defined as the combination of the highest tertile of triglyceride and lowest tertile of HDL-C).

Based on findings of concordance between outcomes reported by investigators and adjudication of outcomes by a centralized endpoint committee in ACCORD (eTable 1 in Supplement 3) The ACCORDION analyses were conducted using outcomes reported by site investigators during both the active (trial) and passive follow-up period, regardless of the original adjudication classification.

\section{Statistical Analysis}

Statistical analyses were done by the ACCORDION Coordinating Center using SAS, version 9.4 (SAS Institute), according to a prespecified plan that was finalized before any analyses began. A nominal 2-tailed level of significance of $P<.05$ was used for all analyses without adjustment for multiple testing.

Baseline characteristics of participants enrolled in ACCORD-Lipid and a comparison of those who consented to the posttrial passive follow-up were summarized using means, standard deviations, and percentages. Effects of the original interventions on lipid levels during the active treatment phase and subsequent follow-up were estimated by calculating the mean lipid levels and 95\% confidence intervals at follow-up visits by treatment group from the date of randomization through the end of the trial and then beyond through the end of ACCORDION. Follow-up for each participant was defined as the time from randomization until the last date for which the participant's health status was available (Figure 1). All comparisons of intervention groups were performed according to the intention-to-treat principle. ${ }^{16}$

Analyses were conducted using both the original mean 4.7 years of treatment (ACCORD) and with addition of the 5 years of passive posttrial follow-up in ACCORDION, for a mean of 9.7 years of follow-up. The number and annual percentage of participants who had a postrandomization event was determined using Kaplan-Meier estimates. Cox proportional hazards regression analyses were used to estimate the long-term effect of allocation to either fenofibrate or placebo on the primary and 
secondary outcomes, using a $\chi^{2}$ statistic from a likelihood ratio test obtained from proportional hazards models with and without the term for intervention arm. Hazard ratios and 95\% confidence intervals were calculated after accounting for variables that were prespecified in the prior ACCORDION analyses. Analyses were conducted on all 5518 ACCORD-Lipid trial participants with censoring of outcomes on the date of the last available information. The consistency of the effect of the study group assignment of the primary outcome and mortality within prespecified subgroups was assessed with the use of statistical tests of interactions between the treatment effect and the subgroup within the Cox models.

\section{Results}

Of the original 5518 men and women enrolled in the ACCORDLipid Trial, ${ }^{9} 4644$ provided written consent to be followed up during the posttrial period, representing $90 \%$ of surviving participants. The baseline characteristics at the time of entry into ACCORD among those consenting to participate in ACCORDION were similar to those of the entire original ACCORD-Lipid cohort including plasma lipoproteins and prevalence of preventive therapies such as statins (Table 1). In contrast, the 874 ACCORD participants who did not consent to post-ACCORD follow-up, including those who died during ACCORD, were older, more likely to be nonwhite, and more likely to have had a prior cardiovascular event, a lower prevalence of statin therapy, and a higher LDL-C on entry into ACCORD (Table 1).

The mean duration of follow-up during ACCORD-Lipid was 4.7 years for the primary outcome and 5.0 years for all-cause mortality. With the addition of posttrial follow-up, the overall mean duration of follow-up was 7.7 years for the primary outcome and 9.1 years for all-cause mortality. The maximum length of follow-up for individual participants was more than 12 years. At the final ACCORD study visit, 4754 of the participants $(86.0 \%)$ remained on a statin and 2137 participants (77.3\%) originally assigned to fenofibrate remained on fenofibrate. ${ }^{9}$ Following completion of ACCORD, further lipid treatment was guided by primary care clinicians who continued to prescribe statin therapy in 2476 ACCORDION participants (74.1\%). In contrast, only 144 ACCORDION participants (4.3\%) were continued or started on fibrate therapy following completion of ACCORD.

\section{Plasma Lipids}

At the time of entry into ACCORD, fasting plasma lipids at baseline were similar between the participants assigned to fenofibrate and placebo ${ }^{9}$ (eFigure 1 in Supplement 3). At entry into ACCORD, 3299 ACCORD-Lipid trial participants (59.8\%) were already on statin therapy, and mean LDL was approximately $100 \mathrm{mg} / \mathrm{dL}$ (Table 1). During ACCORD, all participants were treated with simvastatin at a dose of $20 \mathrm{mg} / \mathrm{d}$ to $40 \mathrm{mg} / \mathrm{d} .{ }^{9} \mathrm{Low}-$ density lipoprotein cholesterol levels progressively decreased to a mean of $80 \mathrm{mg} / \mathrm{dL}$ in the placebo group and 81.1 $\mathrm{mg} / \mathrm{dL}$ in the fenofibrate group over the course of the trial because statin therapy was initiated in all participants and was intensified in response to accrual of safety information and in response to evolving guidelines ${ }^{9,15,17}$ (eFigure 1 in Supplement 3). During the posttrial follow-up period, LDL-C levels declined slightly from a mean of $80.2 \mathrm{mg} / \mathrm{dL}$ at the first follow-up visit to an average of $77 \mathrm{mg} / \mathrm{dL}$ in both groups. During ACCORD, triglyceride levels were reduced by $22 \%$, from a mean of $187 \mathrm{mg} / \mathrm{dL}$ to $145 \mathrm{mg} / \mathrm{dL}$ in participants randomized to fenofibrate and declined $8.7 \%$, from a mean of $186.2 \mathrm{mg} / \mathrm{dL}$ to $170 \mathrm{mg} / \mathrm{dL}$ in those randomized to placebo ${ }^{9}$ (eFigure 1 in Supplement 3). During the posttrial period, triglyceride levels continued to decline in the placebo group and increased in the fenofibrate group to a mean of $160.8 \mathrm{mg} / \mathrm{dL}$ in both groups, reflecting high rates of discontinuation of fibrate therapy following completion of ACCORD (eFigure 1 in Supplement 3). During ACCORD, HDL-C increased 8.4\% in the fenofibrate group (from $38.0 \mathrm{mg} / \mathrm{dL}$ to $41.2 \mathrm{mg} / \mathrm{dL}$ ) and $6.0 \%$ in the placebo group (from $38.2 \mathrm{mg} / \mathrm{dL}$ to $40.5 \mathrm{mg} / \mathrm{dL}$ ). ${ }^{9}$ During the posttrial period, HDL-C levels declined to a mean level of $40.5 \mathrm{mg} / \mathrm{dL}$ in participants originally randomized to fenofibrate to levels comparable with those in participants originally randomized to placebo (eFigure 1 in Supplement 3).

\section{Clinical Outcomes}

Rates of occurrence by treatment assignment and hazard ratios for investigator-reported primary and secondary cardiovascular outcome measures during the entire study period, including extended follow-up, are presented in Table 2. Following a mean of 9.0 total years of follow-up, 508 primary end point events occurred in the fenofibrate group vs 539 in the placebo group (hazard ratio [HR], 0.93; 95\% CI, 0.83-1.05; $P=.25$ ) (Table 2). The annual primary outcome rate was $2.38 \%$ among participants randomized to fenofibrate vs $2.55 \%$ among those randomized to placebo. The HR for the primary end point during extended follow-up in ACCORDION was essentially identical to that observed during the 4.7-year active treatment phase of ACCORD (HR, 0.92; 95\% CI, 0.79-1.08; $P=.32$ ) (Table 2). Thus, the additional 5 years of follow-up did not change the original neutral findings of the ACCORD study. ${ }^{9}$ Similarly, the hazard ratios for the secondary outcomes, including the individual components of the primary outcome, were not statistically different between treatment groups and were comparable with those observed during ACCORD (Table 2). KaplanMeier curves describing the almost 10-year accumulation of major cardiovascular events in the 2 groups visually confirm the comparable rates of accrual of outcomes in the 2 treatment groups (Figure 2).

In contrast to the overall neutral effect of fenofibrate therapy in the entire ACCORD cohort, heterogeneity in the effect of fenofibrate on the primary cardiovascular outcome continued to be observed during extended follow-up in those with dyslipidemia at study entry. During the combined trial plus posttrial period, the primary outcome in study participants with dyslipidemia who were randomized to fenofibrate was $27 \%$ lower than among those with dyslipidemia randomized to placebo but only $1 \%$ lower in nondyslipidemic study participants (HR, 0.73; 95\% CI, 0.56-0.95 vs HR, 0.99; 95\% CI, 0.86-1.13; $P=.05$ for dyslipidemic vs non-dyslipidemic, respectively) (Figure 3). Persistent heterogeneity in fenofibrate 
Table 1. Comparison of ACCORD Baseline Characteristics Between Those Who Consented for Post-ACCORD Follow-up and Those Who Did Not Consent

\begin{tabular}{|c|c|c|c|c|c|}
\hline Baseline Characteristic & $\begin{array}{l}\text { All Lipid Trial } \\
\text { Participants } \\
(\mathrm{n}=5518)\end{array}$ & $\begin{array}{l}\text { Consented for } \\
\text { Post-ACCORD } \\
\text { Follow-up } \\
(\mathrm{n}=4644) \\
\end{array}$ & $\begin{array}{l}\text { Did Not Consent } \\
\text { for Post-ACCORD } \\
\text { Follow-up } \\
(\mathrm{n}=874)\end{array}$ & $\begin{array}{l}\text { Difference } \\
(\mathrm{n}=5518)\end{array}$ & $\begin{array}{l}P \text { Value for } \\
\text { Difference }\end{array}$ \\
\hline Age, mean (SD), y & $62.3(6.8)$ & $62.0(6.6)$ & $63.9(7.5)$ & -1.9 & $<.001$ \\
\hline Female sex, No./total No. (\%) & $1694 / 5518(30.7)$ & $1445 / 4644(31.1)$ & $249 / 874(28.5)$ & 2.6 & .12 \\
\hline \multicolumn{6}{|l|}{ Race/ethnicity, ${ }^{a}$ No./total No. (\%) } \\
\hline White & $3612 / 5518(65.5)$ & $3067 / 4644(66.0)$ & $545 / 874(62.4)$ & 3.6 & \multirow{3}{*}{$<.001$} \\
\hline Black & $826 / 5518(15.0)$ & $655 / 4644(14.1)$ & $171 / 874(19.6)$ & -5.5 & \\
\hline Hispanic & $407 / 5518(7.4)$ & $339 / 4644(7.3)$ & $68 / 874(7.8)$ & -0.5 & \\
\hline \multicolumn{6}{|l|}{ Education, No./total No. (\%) } \\
\hline Less than high school & $750 / 5515(13.6)$ & $588 / 4641(12.7)$ & $162 / 874(18.5)$ & -5.8 & \multirow{4}{*}{$<.001$} \\
\hline High school graduate or GED & $1433 / 5515(26.0)$ & $1184 / 4641(25.5)$ & $249 / 874(28.5)$ & -3.0 & \\
\hline Some college & $1827 / 5515(33.1)$ & $1537 / 4641(33.1)$ & $290 / 874(33.2)$ & -0.1 & \\
\hline College degree or higher & $1505 / 5515(27.3)$ & $1332 / 4641(28.7)$ & $173 / 874(19.8)$ & 8.9 & \\
\hline Previous cardiovascular event, No./total No. (\%) & $2016 / 5518(36.5)$ & $1620 / 4644(34.9)$ & $396 / 874(45.3)$ & -10.4 & $<.001$ \\
\hline Previous congestive heart failure, No./total No. (\%) & $291 / 5508(5.3)$ & $198 / 4644(4.3)$ & $93 / 864(10.8)$ & -6.5 & $<.001$ \\
\hline \multicolumn{6}{|l|}{ Cigarette-smoking status, No./total No. (\%) } \\
\hline Current & $793 / 5510(14.4)$ & $640 / 4638(13.8)$ & $153 / 872(17.5)$ & -3.7 & \multirow{3}{*}{$<.001$} \\
\hline Former & $2546 / 5510(46.2)$ & $2121 / 4638(45.7)$ & $425 / 872(48.7)$ & -3.0 & \\
\hline Never & $2161 / 5510(39.2)$ & $1867 / 4638(40.3)$ & 294/872 (33.7) & 6.6 & \\
\hline Weight, mean (SD), kg & $94.8(18.7)$ & $94.9(18.7)$ & $94.7(18.4)$ & 0.2 & .84 \\
\hline Body mass index, mean (SD) ${ }^{b}$ & $32.3(5.4)$ & $32.3(5.4)$ & $32.4(5.4)$ & -0.1 & .72 \\
\hline \multicolumn{6}{|l|}{ Blood pressure, mean (SD), mm Hg } \\
\hline Systolic & $133.9(17.8)$ & $133.4(17.5)$ & $136.6(6.6)$ & -3.2 & $<.001$ \\
\hline Diastolic & $74.0(10.8)$ & $73.9(10.7)$ & $74.2(11.3)$ & -0.3 & .45 \\
\hline \multicolumn{6}{|l|}{ Medications, No./total No. (\%) } \\
\hline Insulin & $1836 / 5518(33.3)$ & $1511 / 4644(32.5)$ & $325 / 874(37.2)$ & -4.7 & .01 \\
\hline Metformin & $3420 / 5518(62.0)$ & $2943 / 4644(63.4)$ & $477 / 874(54.6)$ & 8.8 & $<.001$ \\
\hline Any sulfonylurea & $2892 / 5518(52.4)$ & $2448 / 4644(52.7)$ & $444 / 874(50.8)$ & 1.9 & .30 \\
\hline Any thiazolidinedione & $973 / 5518(17.6)$ & $840 / 4644(18.1)$ & $133 / 874(15.2)$ & 2.9 & .04 \\
\hline Angiotensin-converting-enzyme inhibitor & $2967 / 5518(53.8)$ & 2499/4644 (53.8) & $468 / 874(53.5)$ & 0.3 & .89 \\
\hline Angiotensin-receptor-blocker & $838 / 5518(15.2)$ & $709 / 4644(15.3)$ & $129 / 874(14.8)$ & 0.5 & .70 \\
\hline Aspirin & $3106 / 5518(56.3)$ & $2626 / 4644(56.5)$ & $480 / 874(54.9)$ & 1.6 & .37 \\
\hline$\beta$-Blocker & $1798 / 5518(32.6)$ & $1488 / 4644(32.0)$ & $310 / 874(35.5)$ & -3.5 & .05 \\
\hline Any thiazide diuretic & $1473 / 5518(26.7)$ & $1251 / 4644(26.9)$ & $222 / 874(25.4)$ & 1.5 & .35 \\
\hline Statin & $3299 / 5518(59.8)$ & $2819 / 4644(60.7)$ & $480 / 874(54.9)$ & 5.8 & .001 \\
\hline Any lipid-lowering agent & $3558 / 5518(64.5)$ & $3036 / 4644(65.4)$ & $522 / 874(59.7)$ & 5.7 & .001 \\
\hline Duration of diabetes, mean (SD), y & $10.6(7.5)$ & $10.6(7.5)$ & $10.9(7.7)$ & -0.3 & .26 \\
\hline \multicolumn{6}{|l|}{ Glycated hemoglobin, \% } \\
\hline Mean (SD) & $8.3(1.0)$ & $8.25(1.01)$ & $8.43(1.15)$ & -0.18 & $<.001$ \\
\hline Median (IQR) & 8.1 (7.6 to 8.8$)$ & $8.1(7.5$ to 8.8$)$ & $8.2(7.7$ to 9.0$)$ & -0.1 & .001 \\
\hline Fasting plasma glucose, mean (SD), mg/dL & $175.8(54.9)$ & $176.1(54.5)$ & $174.2(57.1)$ & 1.9 & .34 \\
\hline Amputation owing to diabetes, No./total No. (\%) & $110 / 5518(2.0)$ & $85 / 4644(1.8)$ & $25 / 874(2.9)$ & -1.1 & .05 \\
\hline Potassium, mean (SD), mg/dL & $4.5(0.4)$ & $4.47(0.42)$ & $4.49(0.46)$ & -0.02 & .41 \\
\hline Serum creatinine, mean (SD), mg/dL & $0.9(0.2)$ & $0.92(0.22)$ & $0.97(0.26)$ & -0.05 & $<.001$ \\
\hline \multicolumn{6}{|l|}{ eGFR (mL/min/1.73m²) } \\
\hline $30-49 \mathrm{~mL} / \mathrm{min} / 1.73 \mathrm{~m}^{2}$ & $141 / 5488(2.6)$ & $102 / 4621(2.2)$ & $39 / 867(4.5)$ & -2.3 & \multirow{2}{*}{$<.001$} \\
\hline$>50 \mathrm{~mL} / \mathrm{min} / 1.73 \mathrm{~m}^{2}$ & $5347 / 5488(97.4)$ & $4519 / 4621(97.8)$ & $828 / 867(95.5)$ & 2.3 & \\
\hline Total plasma cholesterol, mean (SD), mg/dL & $175.2(37.3)$ & 174.7 (36.9) & $177.6(39.4)$ & -2.9 & .04 \\
\hline Plasma LDL-C, mean (SD), mg/dL & $100.6(30.7)$ & $99.9(30.3)$ & $103.9(32.5)$ & -4.0 & .001 \\
\hline
\end{tabular}


Table 1. Comparison of ACCORD Baseline Characteristics Between Those Who Consented for Post-ACCORD Follow-up and Those Who Did Not Consent (continued)

\begin{tabular}{|c|c|c|c|c|c|}
\hline Baseline Characteristic & $\begin{array}{l}\text { All Lipid Trial } \\
\text { Participants } \\
(n=5518)\end{array}$ & $\begin{array}{l}\text { Consented for } \\
\text { Post-ACCORD } \\
\text { Follow-up } \\
(n=4644)\end{array}$ & $\begin{array}{l}\text { Did Not Consent } \\
\text { for Post-ACCORD } \\
\text { Follow-up } \\
(n=874)\end{array}$ & $\begin{array}{l}\text { Difference } \\
(\mathrm{n}=5518)\end{array}$ & $\begin{array}{l}\text { P Value for } \\
\text { Difference }\end{array}$ \\
\hline \multicolumn{6}{|c|}{ Plasma HDL-C, mean (SD), mg/dL } \\
\hline Women & $41.4(7.7)$ & $41.6(7.8)$ & $40.6(7.6)$ & 1.0 & .07 \\
\hline Men & $36.6(7.3)$ & $36.7(7.2)$ & $36.3(7.8)$ & 0.4 & .21 \\
\hline \multicolumn{6}{|c|}{ Plasma triglycerides, mg/dL } \\
\hline Mean (SD) & $187.6(112.6)$ & $188.0(113.4)$ & $185.3(108.3)$ & 2.7 & .53 \\
\hline Median (IQR) & 162 (113 to 229$)$ & 162 (113 to 230$)$ & 162 (112 to 228$)$ & 0.0 & .69 \\
\hline
\end{tabular}

Abbreviations: ACCORD, Action to Control Cardiovascular Risk in Diabetes; ACCORDION, ACCORD Follow-On Study; eGFR, estimated glomerular filtration rate; HDL-C, high-density lipoprotein cholesterol; IQR, interquartile range; LDL-C, low-density lipoprotein cholesterol.

SI conversion factor: To convert creatinine to micromoles per liter, multiply by 76.25; to convert glucose to millimoles per liter, multiply by 0.0555 ; to convert glycated hemoglobin to proportion of total hemoglobin, multiply by 0.01 ; to convert HDL-C to millimoles per liter, multiply by 0.0259; to convert LDL-C to millimoles per liter, multiply by 0.0259 ; to convert potassium to millimoles per liter, multiply by 1 ; to convert triglycerides to millimoles per liter, multiply by 0.0113 .

a Participants could have selected more than 1 racial/ethnic group.

${ }^{\mathrm{b}}$ Calculated as weight in kilograms divided by height in meters squared.

Table 2. Prespecified Primary and Secondary Outcomes by Original Treatment Assignment During ACCORDION Extended Follow-up vs During ACCORD Double-Blind Treatment Phase

\begin{tabular}{|c|c|c|c|c|c|c|}
\hline \multirow[b]{2}{*}{ Outcome } & \multicolumn{2}{|c|}{$\begin{array}{l}\text { Treatment Effect During ACCORD } \\
\text { (Fenofibrate/Placebo) }\end{array}$} & \multicolumn{2}{|c|}{$\begin{array}{l}\text { Hazard Ratios During ACCORDION } \\
\text { (Fenofibrate/Placebo) }\end{array}$} & \multicolumn{2}{|c|}{$\begin{array}{l}\text { Treatment Effect During Extended } \\
\text { Follow-up ACCORD + ACCORDION } \\
{\text { (Fenofibrate/Placebo })^{\mathrm{b}}}\end{array}$} \\
\hline & Hazard Ratio $(95 \% \mathrm{Cl})$ & $P$ Value & Hazard Ratio $(95 \% \mathrm{Cl})$ & $P$ Value & Hazard Ratio $(95 \% \mathrm{CI})$ & $P$ Value \\
\hline Primary outcome ${ }^{c}$ & $0.92(0.79-1.08)$ & .32 & $0.93(0.76-1.34)$ & .47 & $0.93(0.83-1.05)$ & .25 \\
\hline \multicolumn{7}{|l|}{ Secondary outcomes } \\
\hline $\begin{array}{l}\text { Primary outcome plus } \\
\text { revascularization or } \\
\text { hospitalization for } \\
\text { congestive heart failure }\end{array}$ & $0.94(0.85-1.05)$ & .30 & $1.12(0.95-1.32)$ & .20 & $1.00(0.92-1.10)$ & .98 \\
\hline $\begin{array}{l}\text { Major coronary disease } \\
\text { event }^{d}\end{array}$ & $0.92(0.79-1.07)$ & .26 & $0.95(0.77-1.17)$ & .61 & $0.91(0.81-1.03)$ & .13 \\
\hline $\begin{array}{l}\text { Nonfatal myocardial } \\
\text { infarction }\end{array}$ & $0.91(0.74-1.12)$ & .39 & $1.05(0.76-1.44)$ & .78 & $0.93(0.78-1.10)$ & .37 \\
\hline Nonfatal Stroke & $1.17(0.76-1.78)$ & .48 & $0.93(0.65-1.32)$ & .67 & $1.12(0.87-1.43)$ & .38 \\
\hline Fatal or nonfatal stroke & $1.05(0.71-1.56)$ & .80 & $1.01(0.71-1.42)$ & .97 & $1.12(0.89-1.42)$ & .33 \\
\hline All-cause mortality & $0.91(0.75-1.10)$ & .34 & $0.96(0.83-1.11)$ & .57 & $0.94(0.84-1.06)$ & .32 \\
\hline Cardiovascular mortality & $0.86(0.66-1.12)$ & .26 & $0.82(0.63-1.07)$ & .14 & $0.84(0.69-1.01)$ & .07 \\
\hline $\begin{array}{l}\text { Fatal or nonfatal congestive } \\
\text { heart failure }\end{array}$ & $0.82(0.65-1.05)$ & .10 & $0.85(0.67-1.06)$ & .15 & $0.86(0.71-1.05)$ & .14 \\
\hline $\begin{array}{l}\text { Nonfatal myocardial } \\
\text { Infarction, nonfatal stroke } \\
\text { or all cause mortality }\end{array}$ & $\mathrm{NR}^{\mathrm{a}}$ & $N R^{a}$ & $0.98(0.84-1.13)$ & .74 & $0.97(0.88-1.07)$ & .58 \\
\hline \multicolumn{3}{|c|}{$\begin{array}{l}\text { Abbreviations: ACCORD, Action to Control Cardiovascular Risk in Diabetes; } \\
\text { ACCORDION, ACCORD Follow-On Study; NR, not reported by Ginsberg et al }{ }^{9} \\
\text { because it was not an ACCORD Protocol Outcome. }\end{array}$} & $\begin{array}{l}\text { ACCORDION (e } \\
\text { c Primary outcon } \\
\text { myocardial infa }\end{array}$ & $\begin{array}{l}\text { tended po } \\
\text { for origir } \\
\text { tion, non }\end{array}$ & $\begin{array}{l}\text { y passive follow-up peric } \\
\text { ORD study, combined or } \\
\text { roke, and fatal cardiovas }\end{array}$ & $\begin{array}{l}\text { rence of nonfatal } \\
\text { r event. }\end{array}$ \\
\hline \multicolumn{3}{|c|}{$\begin{array}{l}\text { a Hazard ratio of events occurring during ACCORD, ACCORDION alone, and } \\
\text { combined. Number and event rate during combined follow-up (ACCORD and } \\
\text { ACCORDION) in study participants originally randomized to fenofibrate vs } \\
\text { placebo. }{ }^{18}\end{array}$} & \multicolumn{4}{|c|}{$\begin{array}{l}\text { d A major coronary disease event was defined as a fatal coronary event, nonfatal } \\
\text { myocardial infarction, or unstable angina. } \\
\text { e New outcome measure; all other outcomes are an original ACCORD protocol } \\
\text { outcome. }\end{array}$} \\
\hline
\end{tabular}

response was also observed in men vs women, and the primary outcome in the fenofibrate treatment group was $16 \%$ lower for men but 30\% higher for women (HR, 0.84; 95\% CI, 0.73-0.96 vs HR, 1.30; 95\% CI, 1.10-1.68; $P=.003$ for men vs women, respectively) (Figure 3). These HRs are nearly identical to those observed in the original ACCORD trial (eTable 2 in Supplement 3). ${ }^{9}$

\section{Discussion}

Up to $35 \%$ of patients with type 2 diabetes are at increased risk of atherosclerotic CVD events related to the presence of diabetic dyslipidemia, defined as hypertriglyceridemia and the associated accumulation of remnant particles, low HDL-C, and 
A Primary outcome

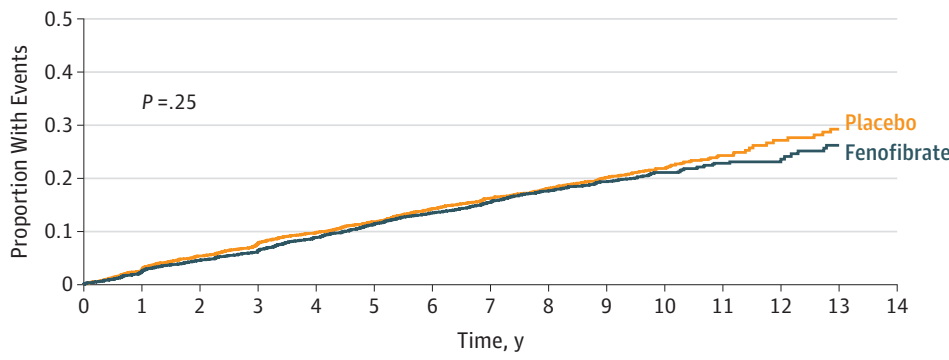

No. at risk

Fenofibrate $\begin{array}{lllllllllllllll}2765 & 2639 & 2555 & 2468 & 2354 & 2212 & 1918 & 1712 & 1543 & 1294 & 769 & 335 & 151 & 129\end{array}$

$\begin{array}{llllllllllllllll}\text { Placebo } & 2753 & 2626 & 2519 & 2430 & 2327 & 2198 & 1902 & 1697 & 1520 & 1279 & 765 & 325 & 147 & 122\end{array}$

B Total mortality

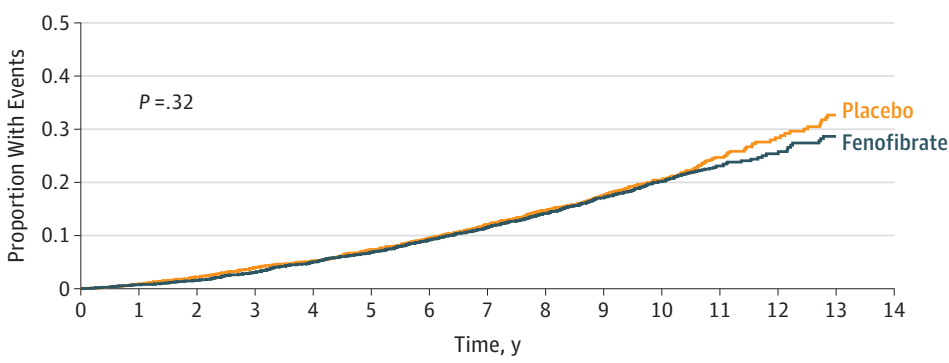

No. at risk

Fenofibrate $\begin{array}{lllllllllllllll}2765 & 2745 & 2722 & 2678 & 2620 & 2567 & 2491 & 2415 & 2131 & 1682 & 968 & 466 & 185 & 160\end{array}$

Placebo $\quad \begin{array}{lllllllllllllll}2753 & 2728 & 2690 & 2641 & 2601 & 2540 & 2462 & 2378 & 2097 & 1674 & 970 & 455 & 175 & 144\end{array}$

C Primary outcome/revascularization/congestive heart failure

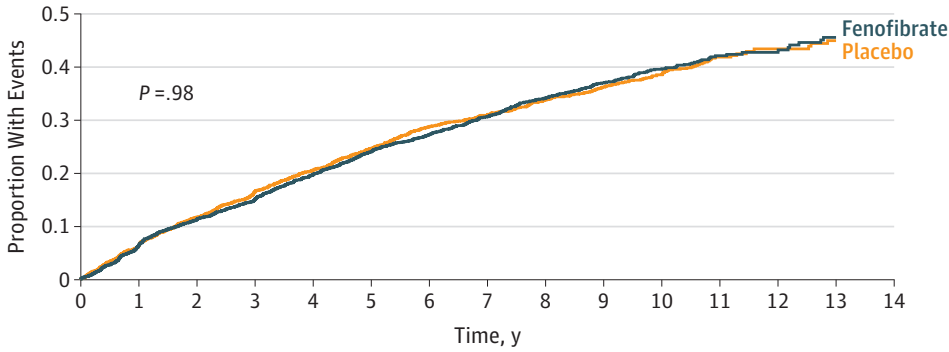

No. at risk

Fenofibrate $\begin{array}{lllllllllllllll}2765 & 2532 & 2377 & 2241 & 2078 & 1899 & 1623 & 1429 & 1254 & 1033 & 595 & 255 & 124 & 106\end{array}$

$\begin{array}{llllllllllllllll}\text { Placebo } & 2753 & 2529 & 2352 & 2201 & 2051 & 1886 & 1582 & 1402 & 1239 & 1024 & 611 & 250 & 116 & 97\end{array}$

D Cardiovascular disease mortality

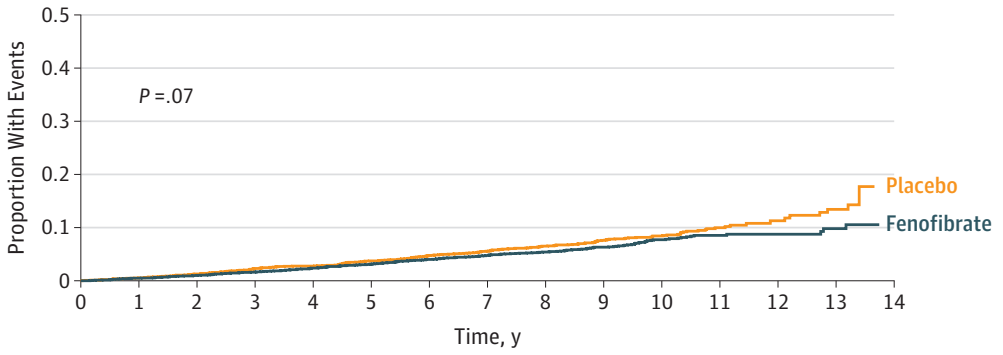

No. at risk

Fenofibrate $\begin{array}{lllllllllllllll}2765 & 2745 & 2722 & 2678 & 2620 & 2567 & 2491 & 2415 & 2131 & 1682 & 968 & 466 & 185 & 160\end{array}$

Placebo $\quad \begin{array}{lllllllllllllll}2753 & 2728 & 2690 & 2641 & 2601 & 2540 & 2462 & 2378 & 2097 & 1674 & 970 & 445 & 175 & 144\end{array}$

The cumulative incidence of the primary outcome (nonfatal myocardial infarction, nonfatal stroke, or death from cardiovascular causes) (A), the expanded macrovascular outcome (a combination of the primary outcome plus revascularization or hospitalization for congestive heart failure) (B), and death from any cause (C) or from cardiovascular causes (D) during follow-up. 


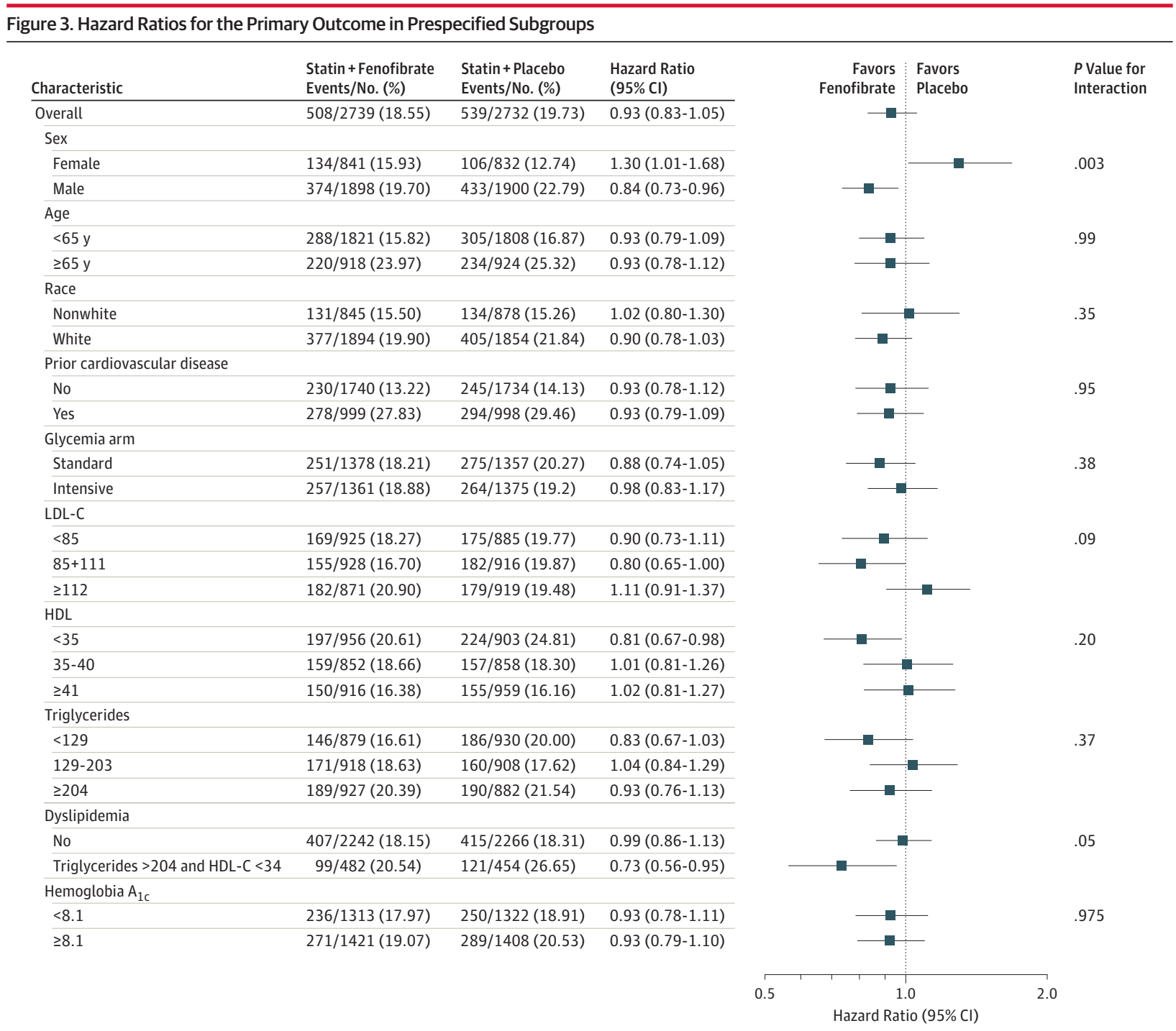

The horizontal bars represent $95 \%$ confidence intervals, and the vertical dashed line indicates the overall hazard ratio. $P$ values are for tests for interaction. HDL-C indicates high-density lipoprotein and LDL-C indicates low-density lipoprotein cholesterol.
To convert the values for cholesterol to millimoles per liter, multiply by 0.02586 . To convert the values for triglycerides to millimoles per liter, multiply by 0.0112 . small dense LDL. ${ }^{8,19}$ However, it is unclear whether pharmacologic therapy directed toward reversing these abnormalities will result in reduced risk of CVD. Although the cardiovascular efficacy of niacin and fibrate (gemfibrozil) monotherapy was clearly established by prestatin-era clinical trials, ${ }^{2 \mathrm{O}-22}$ subsequent trials failed to demonstrate efficacy of newer fibrates, specifically fenofibrate and bezafibrate either alone $e^{23,24}$ or in combination with statin. ${ }^{9}$ Furthermore, between 2007 and 2016, a number of trials testing various triglyceride-lowering and HDL-C-raising medical therapies have failed to demonstrate benefit of add-on therapy in statin-treated patients. ${ }^{25-28}$ These clinical trial outcomes are reflected in treatment guidelines promulgated by the American Heart Association and the American College of Cardiology that focus on recommendations for statin therapy but do not clearly advocate the use of triglyceride-lowering therapy for CVD prevention. ${ }^{29}$
In the case of fenofibrate, 2 cardiovascular end point trials conducted within the last decade failed to show benefit with administration of fenofibrate in patients with type 2 diabetes either alone in the FIELD study ${ }^{24}$ or as add-on therapy to statin in the ACCORD study. ${ }^{9}$ Among the possible reasons for the neutral outcome of FIELD was a disproportionately higher drop in statin therapy in the fenofibrate group. ${ }^{24}$ In ACCORD, one possible reason for failure to demonstrate benefit of add-on fenofibrate therapy was that the treatment duration of 4.7 years was not sufficient to detect a treatment effect. The goal of ACCORDION was to extend the study with an additional 5.0 years of passive follow-up to detect emergence of a "legacy" effect of fenofibrate treatment, similar to that observed in the niacin arm of the Coronary Drug Project ${ }^{30}$ and with glucose lowering in both the United Kingdom Prospective Diabetes Study and the 2008 Veterans Affairs Diabetes Trial. ${ }^{31,32}$ A legacy effect did not emerge during extended follow-up in 
ACCORDION, thus confirming the original overall ACCORD observations. On the other hand, the lower cardiovascular event rates observed among the subgroup of participants with hypertriglyceridemia and low HDL-C who were randomized to fenofibrate therapy during the active treatment phase of ACCORD continued to be observed during the extended follow-up period. These findings support the hypothesis that individuals with diabetic dyslipidemia may benefit from add-on fenofibrate therapy. This hypothesis is supported by the comparable findings of similar subgroup analyses of several major fibrate trials including the FIELD study, ${ }^{33}$ the Helsinki Heart Study (HHS), ${ }^{34}$ Bezafibrate Infarction Prevention Trial (BIP),${ }^{23}$ and VA-HDL Intervention Trial (VA-HIT). ${ }^{35}$ Insofar as the triglyceride-lowering effect of fibrates is greatest among patients with hypertriglyceridemia, ${ }^{34}$ it is not totally unexpected that individuals with hypertriglyceridemia would be most likely to benefit from fibrate therapy. This was clearly evident in the lipid response to fenofibrate in the hypertriglyceridemia/low-HDL-C subset of ACCORD-Lipid participants (eFigure 2 and eFigure 3 in Supplement 3). However, in ACCORD-Lipid, this subset comprised only $17 \%$ of all participants $(\mathrm{n}=941) .^{9}$

The sex differences in fenofibrate response observed in ACCORD $^{9}$ were also observed during extended follow-up in ACCORDION. The observation of sex differences in cardiovascular outcomes with fenofibrate treatment, with men appearing to benefit vs evidence of possible harm in women in ACCORD $^{9}$ and now with extended follow-up in ACCORDION, is both unexpected and unexplained, particularly because similar heterogeneity in fenofibrate treatment effect by sex was not observed in the FIELD trial. ${ }^{24}$ These differences may be attributed to lower numbers of women participants in ACCORD vs FIELD as well as unexpectedly low event rates among placebotreated women in ACCORD. ${ }^{36}$ Therefore, the sex difference may be a chance finding.

It is important to note in the context of our findings that the safety profile of combination therapy with fenofibrate and statin appears to be acceptable. Specifically, in ACCORD, fe- nofibrate was used in combination with simvastatin in more than 2500 patients for a mean of 4.7 years without increased incidence of muscle or liver toxicity. ${ }^{9}$ This is in distinct contrast to the increased risk of myopathy that occurs with coadministration of the fibrate gemfibrozil and statin owing to a known pharmacokinetic interaction. ${ }^{37,38}$ It is also important to note that in ACCORD, fenofibrate treatment slowed progression of diabetic microvascular disease including retinopathy and nephropathy. ${ }^{9,18}$ On the other hand, reversible increases in creatinine and paradoxical lowering of HDL-C were also observed with increased frequency in those randomized to fenofibrate in ACCORD-Lipid. ${ }^{39,40}$

\section{Limitations}

It is also important to note that these prespecified subgroup analyses can only be considered hypothesis-generating and in some cases are based on a relatively small number of events. Although analyses beyond the original predefined primary outcome measure cannot be considered definitive and therefore not suitable for guideline formulation or product labeling, they inform refinement of our original hypothesis for further testing and provide useful information to clinical practitioners regarding possible treatment for diabetic dyslipidemia.

\section{Conclusions}

In conclusion, an additional 5 years of follow-up of surviving ACCORD-Lipid study cohort members extends the original overall neutral outcome of the ACCORD study and provides additional support for possible benefit of fenofibrate therapy in patients with type 2 diabetes in whom triglycerides remain elevated and HDL-C levels remain low despite statin therapy. Our findings support the hypothesis that patients with diabetic dyslipidemia may derive some benefit from add-on triglyceridelowering therapy. Randomized trials testing the cardiovascular efficacy of fibrate as well as other triglyceride-lowering treatments in this specific patient population are needed.

\section{ARTICLE INFORMATION}

Accepted for Publication: October 15, 2016

Correction: This article was corrected on February 6, 2017.

Published Online: December 28, 2016. doi:10.1001/jamacardio.2016.4828

Author Affiliations: Memphis Veterans Affairs Medical Center and University of Tennessee Health Sciences Center, Memphis (Elam); Columbia University College of Physicians and Surgeons, New York, New York (Ginsberg, Lopez, Friedewald); Wake Forest School of Medicine, Wake Forest, North Carolina (Lovato, Byington); University of Washington, Seattle (Corson, Probstfield); University of North Carolina, Chapel Hill (Largay, Buse); Li Ka Shing Knowledge Institute and Keenan Research Centre for Biomedical Science, St. Michael's Hospital, University of Toronto, Ontario, Canada (Leiter); HealthPartners Institute, Minneapolis, Minnesota (O'Connor); Atlanta Veterans Affairs Medical Center, Atlanta, Georgia
(Sweeney); Diabetes Endocrine Nutrition Group, Mentor, Ohio (Weiss); McMaster Medical Center, Hamilton, Ontario, Canada (Gerstein); Berman Center for Outcomes and Clinical Research, Minneapolis, Minnesota (Grimm); Cleveland Veterans Affairs Medical Center, Cleveland, Ohio (Ismail-Beigi); Colorado School of Public Health, Aurora, Colorado (Goff); National Heart, Lung, and Blood Institute, Division of Cardiovascular Sciences, Bethesda, Maryland (Fleg, Rosenberg).

Author Contributions: Drs Elam and Ginsberg had full access to all the data and take responsibility for the integrity of the data and the accuracy of the data analysis.

Concept and design: Elam, Ginsberg, Largay, Leiter, Lopez, O'Connor, Friedewald, Buse, Gerstein, Probstfield, Grimm, Goff, Rosenberg, Byington. Acquisition, analysis, or interpretation of data: Elam, Ginsberg, Lovato, Corson, Leiter, O'Connor, Sweeney, Weiss, Buse, Gerstein, Probstfield, Grimm, IsmailBeigi, Goff, Fleg, Rosenberg, Byington. Drafting of the manuscript: Elam, Ginsberg, Lovato, Byington.
Critical revision of the manuscript for important intellectual content: Elam, Lovato, Corson, Largay, Leiter, Lopez, O'Connor, Sweeney, Weiss. Friedewald, Buse, Gerstein, Probstfield, Grimm, Ismail-Beigi, Goff, Fleg, Rosenberg, Byington. Statistical analysis: Lovato, O'Connor, Byington. Obtained funding: Gerstein.

Administrative, technical, or material support: Lopez, O'Connor, Probstfield, Fleg, Rosenberg, Byington.

Supervision: Grimm

Conflict of Interest Disclosures: All authors have completed and submitted the ICMJE Form for Disclosure of Potential Conflicts of Interest. Dr Ginsberg reports receiving grants and personal fees from Merck outside the submitted work. Dr Largay reports grants from the National Institutes of Health/National Heart, Lung, and Blood Institute during the conduct of the study; personal fees from AstraZeneca, Sanofi Aventis, Takeda, and Vivus; and grants from Andromeda, Boehringer Ingelheim, GI Dynamics, Halozyme, Hoffman-LaRoche, Immune Tolerance Network, 
Johnson and Johnson, Lexicon, Lilly, Medtronic, Merck, Novo Nordisk, Orixigen, Phase Bio, National Institute of Allergy and Infectious Diseases, Sanofi Aventis, Takeda, and Tolerx; and personal fees from Quadrant Healthcare, Medical Logix, Creative Educational Concepts, Institute for Medical and Nursing Education, and Global Academy for Medical Education outside the submitted work. Dr Largay is an employee of AstraZeneca as a Clinical Science Liaison in Diabetes Medical Affairs. Dr Leiter reports personal fees from Aegerion; grants and personal fees from Amgen, AstraZeneca, Boehringer Ingelheim, Eli Lilly, Janssen, Merck, Novo Nordisk, Sanofi, and Servier; and grants from GlaxoSmithKline and Pfizer outside the submitted work. Dr Buse reports grants and fees from Eli Lilly, Bristol-Myers Squibb, GI Dynamics, Amylin, Orexigen, Merck, Novo Nordisk, AstraZeneca, Takeda, Sanofi, and Lexicon; fees from Hoffmann-La Roche, Liposcience, Elcylex, Metavention, vTv Pharma (formerly Transtech Pharma), Dance Biopharm, Quest, and Medtronic Minimed; personal fees from PhaseBio; and grants from Tolerex, Osiris, Halozyme, Pfizer, Johnson and Johnson, Andromeda, Boehringer-Ingelheim, GlaxoSmithKline, Astellas, MacroGenics, Intarcia Therapeutics, and Scion NeuroStim outside the submitted work. Dr Buse is a member of a variety of nonprofit boards including American Diabetes Association, DiabetesSisters, Taking Control of Your Diabetes, AstraZeneca Healthcare Foundation, Bristol-Myers Squib Together on Diabetes Foundation, and the National Diabetes Education Program. Dr Gerstein reports grants and personal fees from Sanofi, Lilly, AstraZeneca, Boehringer Ingelheim, Novo Nordisk, Merck; grants from Jansen; and personal fees from Abbott, Berlin Chemie, Amgen, Kaneq Bioscience, Roche, and GlaxoSmithKline outside the submitted work. Dr Probstfield reports grants and personal fees from Sanofi. Dr Ismail-Beigi reports grants from the National Institutes of Health and Novo Nordisk and fees from Eli Lilly, Thermalin Diabetes, and COVANCE outside the submitted work. Dr Goff reports grants from the National Institutes of health outside the submitted work. Dr Byington reports personal fees from Eli Lilly and Company. No other disclosures were reported.

Funding/Support: This work was supported by National Heart, Lung, and Blood Institute contracts N01-HC-95178, N01-HC-95179, N01-HC-95180, N01-HC-95181, NO1-HC-95182, N01-HC-95183, N01-HC-95184, and Interagency Agreements Y1-HC-9035 and Y1-HC-1010. Other components of the National Institutes of Health, including the National Institute of Diabetes and Digestive and Kidney Diseases, the National Institute on Aging and the National Eye Institute contributed funding. The Centers for Disease Control and Prevention funded substudies within ACCORD on cost-effectiveness and health-related quality of life. General Clinical Research Centers and Clinical Translational Science Awards provided support at many sites. This material is also the result of work supported with resources and the use of facilities at the Veterans Affairs medical centers as listed previously. ${ }^{41}$ ACCORDION activities were supported by National Heart Lung and Blood Institute contract HHSN268201100027C. During ACCORD, the following companies provided study medications, equipment, or supplies: Abbott Laboratories; Amylin Pharmaceutical; Astra Zeneca Pharmaceuticals LP; Bayer HealthCare LLC; Closer
Healthcare Inc; GlaxoSmithKline Pharmaceuticals; King Pharmaceuticals, Inc; Merck and Co Inc; Novartis Pharmaceuticals Inc; Novo-Nordisk Inc; Omron Healthcare Inc; Sanofi-Aventis US; Schering-Plough Corporation; Takeda Pharmaceuticals.

Role of the Funder/Sponsor: ACCORD and ACCORDION were multicenter clinical trials supported by the National, Heart, Lung, and Blood Institute. The trial was designed and directed by a steering committee consisting of study investigators and representatives of the Wake Forest University Coordinating Center and National Heart, Lung, and Blood Institute. All data analysis was performed by the study Coordinating Center at Wake Forest University under supervision of the Director, Robert Byington. Companies contributing materials for the trial had no role in the design or conduct of the study, the management or analyses performed in the study, or the interpretation of the data. Before submission for publication, the ACCORD/ACCORDION Steering Committee approved the manuscript. In their role on the Steering Committee as representatives of the sponsoring agency National Institute of Diabetes and Digestive and Kidney Diseases, Drs Fleg and Rosenberg participated in the design and conduct of the study; collection, management, analysis, and interpretation of the data; approval and decision to submit the manuscript for publication.

Disclaimer: The contents do not represent the views of the National Institutes of Health, the US Department of Veterans Affairs, or the US Government.

\section{REFERENCES}

1. Almdal T, Scharling $H$, Jensen JS, Vestergaard $H$. The independent effect of type 2 diabetes mellitus on ischemic heart disease, stroke, and death: a population-based study of 13,000 men and women with 20 years of follow-up. Arch Intern Med. 2004;164(13):1422-1426

2. Stamler J, Vaccaro O, Neaton JD, Wentworth D. Diabetes, other risk factors, and 12-yr cardiovascular mortality for men screened in the Multiple Risk Factor Intervention Trial. Diabetes Care. 1993;16(2):434-444

3. Haffner SM, Lehto S, Rönnemaa T, Pyörälä K, Laakso M. Mortality from coronary heart disease in subjects with type 2 diabetes and in nondiabetic subjects with and without prior myocardial infarction. N Engl J Med. 1998;339(4):229-234.

4. Miettinen $H$, Lehto $S$, Salomaa $V$, et al; The FINMONICA Myocardial Infarction Register Study Group. Impact of diabetes on mortality after the first myocardial infarction. Diabetes Care. 1998 21(1):69-75

5. Chahil TJ, Ginsberg HN. Diabetic dyslipidemia. Endocrinol Metab Clin North Am. 2006;35(3):491-510, vii-viii.

6. Turner RC, Millns H, Neil HA, et al. Risk factors for coronary artery disease in non-insulin dependent diabetes mellitus: United Kingdom Prospective Diabetes Study (UKPDS: 23). BMJ. 1998;316(7134):823-828.

7. Buse JB, Bigger JT, Byington RP, et al; ACCORD Study Group. Action to Control Cardiovascular Risk in Diabetes (ACCORD) trial: design and methods. Am J Cardiol. 2007;99(12A):21i-33i.
8. Miller M, Stone NJ, Ballantyne C, et al; American Heart Association Clinical Lipidology, Thrombosis, and Prevention Committee of the Council on Nutrition, Physical Activity, and Metabolism; Council on Arteriosclerosis, Thrombosis and Vascular Biology; Council on Cardiovascular Nursing; Council on the Kidney in Cardiovascular Disease. Triglycerides and cardiovascular disease: a scientific statement from the American Heart Association. Circulation. 2011:123(20):2292-2333.

9. Ginsberg HN, Elam MB, Lovato LC, et al; ACCORD Study Group. Effects of combination lipid therapy in type 2 diabetes mellitus. $N$ Engl J Med. 2010;362(17):1563-1574.

10. Gerstein HC, Miller ME, Byington RP, et al; Action to Control Cardiovascular Risk in Diabetes Study Group. Effects of intensive glucose lowering in type 2 diabetes. N Engl J Med. 2008;358(24): 2545-2559.

11. Cushman WC, Evans GW, Byington RP, et al; ACCORD Study Group. Effects of intensive blood-pressure control in type 2 diabetes mellitus. N Engl J Med. 2010;362(17):1575-1585.

12. Gerstein HC, Miller ME, Genuth S, et al; ACCORD Study Group. Long-term effects of intensive glucose lowering on cardiovascular outcomes. N Engl J Med. 2011;364(9):818-828.

13. ACCORD Study Group. Nine-year effects of 3.7 years of intensive glycemic control on cardiovascular outcomes. Diabetes Care. 2016;39 (5):701-770.

14. Goff DC Jr, Gerstein HC, Ginsberg HN, et al; ACCORD Study Group. Prevention of cardiovascular disease in persons with type 2 diabetes mellitus: current knowledge and rationale for the Action to Control Cardiovascular Risk in Diabetes (ACCORD) trial. Am J Cardiol. 2007;99(12A):4i-20i.

15. Ginsberg HN, Bonds DE, Lovato LC, et al; ACCORD Study Group. Evolution of the lipid trial protocol of the Action to Control Cardiovascular Risk in Diabetes (ACCORD) trial. Am J Cardiol. 2007; 99(12A):56i-67i.

16. Harmonised Tripartite Guideline ICH. ICH Harmonised Tripartite Guideline. Statistical principles for clinical trials. International Conference on Harmonisation E9 Expert Working Group. Stat Med. 1999;18(15):1905-1942.

17. Grundy SM, Cleeman Jl, Merz CN, et al; National Heart, Lung, and Blood Institute; American College of Cardiology Foundation; American Heart Association. Implications of recent clinical trials for the National Cholesterol Education Program Adult Treatment Panel III guidelines. Circulation. 2004; $110(2): 227-239$.

18. Chew EY, Ambrosius WT, Davis MD, et al: ACCORD Study Group; ACCORD Eye Study Group. Effects of medical therapies on retinopathy progression in type 2 diabetes. N Engl J Med. 2010; 363(3):233-244.

19. Resnick HE, Foster GL, Bardsley J, Ratner RE. Achievement of American Diabetes Association clinical practice recommendations among U.S adults with diabetes, 1999-2002: the National Health and Nutrition Examination Survey. Diabetes Care. 2006;29(3):531-537.

20. Clofibrate and niacin in coronary heart disease. JAMA. 1975;231(4):360-381.

21. Rubins HB, Robins SJ, Collins $D$, et al; Veterans Affairs High-Density Lipoprotein Cholesterol 
Intervention Trial Study Group. Gemfibrozil for the secondary prevention of coronary heart disease in men with low levels of high-density lipoprotein cholesterol. N Engl J Med. 1999;341(6):410-418.

22. Frick MH, Elo O, Haapa K, et al. Helsinki Heart Study: primary-prevention trial with gemfibrozil in middle-aged men with dyslipidemia. Safety of treatment, changes in risk factors, and incidence of coronary heart disease. N Engl J Med. 1987;317(20): 1237-1245.

23. Bezafibrate Infarction Prevention (BIP) study. Secondary prevention by raising HDL cholesterol and reducing triglycerides in patients with coronary artery disease. Circulation. 2000;102(1):21-27.

24. Keech A, Simes RJ, Barter P, et al; FIELD study investigators. Effects of long-term fenofibrate therapy on cardiovascular events in 9795 people with type 2 diabetes mellitus (the FIELD study): randomised controlled trial. Lancet. 2005;366 (9500):1849-1861.

25. Schwartz GG, Olsson AG, Abt M, et al: dal-OUTCOMES Investigators. Effects of dalcetrapib in patients with a recent acute coronary syndrome. N Engl J Med. 2012;367(22):2089-2099.

26. Boden WE, Probstfield JL, Anderson T, et al; AIM-HIGH Investigators. Niacin in patients with low $\mathrm{HDL}$ cholesterol levels receiving intensive statin therapy. N Engl J Med. 2011;365(24):2255-2267.

27. Landray MJ, Haynes R, Hopewell JC, et al; HPS2-THRIVE Collaborative Group. Effects of extended-release niacin with laropiprant in high-risk patients. N Engl J Med. 2014;371(3): 203-212.

28. Barter PJ, Caulfield M, Eriksson M, et al; ILLUMINATE Investigators. Effects of torcetrapib in patients at high risk for coronary events. N Engl J Med. 2007;357(21):2109-2122

29. Stone NJ, Robinson JG, Lichtenstein $A H$, et al American College of Cardiology/American Heart Association Task Force on Practice Guidelines. 2013 ACC/AHA guideline on the treatment of blood cholesterol to reduce atherosclerotic cardiovascular risk in adults: a report of the American College of Cardiology/American Heart Association Task Force on Practice Guidelines. Circulation. 2014;129(25) (suppl 2):S1-S45.

30. Canner PL, Berge KG, Wenger NK, et al. Fifteen year mortality in Coronary Drug Project patients: long-term benefit with niacin. J Am Coll Cardiol. 1986;8(6):1245-1255

31. Hayward RA, Reaven PD, Wiitala WL, et al; VADT Investigators. Follow-up of glycemic control and cardiovascular outcomes in type 2 diabetes. N Engl J Med. 2015;372(23):2197-2206.

32. Holman RR, Paul SK, Bethel MA, Matthews DR, Neil HA. 10-year follow-up of intensive glucose control in type 2 diabetes. N Engl J Med. 2008;359 (15):1577-1589.

33. Scott R, O'Brien R, Fulcher G, et al; Fenofibrate Intervention and Event Lowering in Diabetes (FIELD) Study Investigators. Effects of fenofibrate treatment on cardiovascular disease risk in 9,795 individuals with type 2 diabetes and various components of the metabolic syndrome: the Fenofibrate Intervention and Event Lowering in Diabetes (FIELD) study. Diabetes Care. 2009;32(3): 493-498.

34. Manninen V, Elo MO, Frick MH, et al. Lipid alterations and decline in the incidence of coronary heart disease in the Helsinki Heart Study. JAMA. 1988;260(5):641-651.
35. Robins SJ, Collins D, Wittes JT, et al; VA-HIT Study Group. Veterans Affairs High-Density Lipoprotein Intervention Trial. Relation of gemfibrozil treatment and lipid levels with major coronary events: VA-HIT: a randomized controlled trial. JAMA. 2001;285(12):1585-1591.

36. d'Emden MC, Jenkins AJ, Li L, et al; FIELD Study Investigators. Favourable effects of fenofibrate on lipids and cardiovascular disease in women with type 2 diabetes: results from the Fenofibrate Intervention and Event Lowering in Diabetes (FIELD) study. Diabetologia. 2014;57(11): 2296-2303.

37. Jones $\mathrm{PH}$, Davidson $\mathrm{MH}$. Reporting rate of rhabdomyolysis with fenofibrate + statin versus gemfibrozil + any statin. Am J Cardiol. 2005;95(1): 120-122.

38. Prueksaritanont T, Tang C, Qiu Y, Mu L, Subramanian R, Lin JH. Effects of fibrates on metabolism of statins in human hepatocytes. Drug Metab Dispos. 2002;30(11):1280-1287.

39. Mychaleckyj JC, Craven T, Nayak U, et al. Reversibility of fenofibrate therapy-induced renal function impairment in ACCORD type 2 diabetic participants. Diabetes Care. 2012;35(5):1008-1014.

40. Linz PE, Lovato LC, Byington RP, et al. Paradoxical reduction in HDL-C with fenofibrate and thiazolidinedione therapy in type 2 diabetes: the ACCORD Lipid Trial. Diabetes Care. 2014;37(3) 686-693.

41. Gerstein HC, Miller ME, Byington RP, et al; Action to Control Cardiovascular Risk in Diabetes Study Group. Effects of intensive glucose lowering in type 2 diabetes. N Engl J Med. 2008;358(24): 2545-2559. 